\title{
Dry Growth of N-octylphosphonic Acid Monolayer for Low-Voltage Organic Thin-Film Transistors
}

\author{
S. Gupta and H. Gleskova \\ Department of Electronic and Electrical Engineering, University of Strathclyde, Glasgow, \\ G1 1XW, United Kingdom
}

\begin{abstract}
Dry method for monolayer deposition of n-octylphosphonic acid $\left(\mathrm{C}_{8} \mathrm{PA}\right)$ on the surface of aluminium oxide $\left(\mathrm{AlO}_{\mathrm{x}}\right)$ is presented. Vacuum thermal evaporation is employed to deposit initial thickness corresponding to several $\mathrm{C}_{8} \mathrm{PA}$ monolayers, followed by a thermal desorption of the physisorbed $\mathrm{C}_{8} \mathrm{PA}$ molecules. $\mathrm{AlO}_{\mathrm{x}}$ functionalized with such $\mathrm{C}_{8} \mathrm{PA}$ monolayer exhibits leakage current density of $\sim 10^{-7} \mathrm{~A} / \mathrm{cm}^{2}$ at $3 \mathrm{~V}$, electric breakdown field of $\sim 6 \mathrm{MV} / \mathrm{cm}$, and a root-mean-square surface roughness of $0.36 \mathrm{~nm}$. The performance of low-voltage pentacene thin-film transistors that implement this dry $\mathrm{AlO}_{\mathrm{x}} / \mathrm{C}_{8} \mathrm{PA}$ gate dielectric depends on $\mathrm{C}_{8} \mathrm{PA}$ desorption time. When the desorption time rises from 25 to 210 minutes, the field-effect mobility increases from $\sim 0.02$ to $\sim 0.04 \mathrm{~cm}^{2} / \mathrm{Vs}$, threshold voltage rises from $\sim-1.2$ to $\sim-1.4 \mathrm{~V}$, sub-threshold slope decreases from $\sim 120$ to $\sim 80 \mathrm{mV} /$ decade, offcurrent decreases from $\sim 5 \times 10^{-12}$ to $\sim 1 \times 10^{-12} \mathrm{~A}$, on/off current ratio rises from $\sim 3.8 \times 10^{4}$ to $\sim 2.5 \times 10^{5}$, and the transistor hysteresis decreases from 61 to $26 \mathrm{mV}$. These results collectively support a two stage model of the desorption process where the removal of the physisorbed $\mathrm{C}_{8}$ PA molecules is followed by the annealing of the defect sites in the remaining $\mathrm{C}_{8} \mathrm{PA}$ monolayer.
\end{abstract}

Keywords: organic thin-film transistor, aluminium oxide, alkyl phosphonic acid, pentacene, monolayer formation in vacuum

Contact author: Swati Gupta, swati.gupta@ strath.ac.uk

Second author: Helena Gleskova, helena.gleskova@strath.ac.uk 


\section{Introduction}

The use of organic thin-film transistors (OTFTs) in inverters [1-4], Braille displays [5], amplifiers and NAND or NOR digital gates [6] aims for reduction in their operating voltages. Low transistor operating voltage reduces power consumption in the electronic circuits and is one of the primary concerns of very large scale integrated devices. High capacitance of the gate dielectric is a key approach to low voltage transistor operation. High capacitance values can be achieved with high-k and/or ultra-thin dielectrics.

High capacitance has been obtained by using high-k dielectrics such as polymers $(\mathrm{k} \sim$ 12.6) [7] and metal oxides, e.g. $\mathrm{HfLaO}(\mathrm{k} \sim 15.3)$ [8-10] $\mathrm{Ba}_{1.2} \mathrm{Ti}_{0.8} \mathrm{O}_{3}(\mathrm{k} \sim 15.57)$ [11], and $\mathrm{SrTiO}_{3}(\mathrm{k} \sim 12.1)$ [12]. Thick high-k dielectrics resulted in still high capacitance values while reducing the gate leakage current. However, with the exceptions of [10], such OTFTs typically exhibited high inverse subthreshold slope $[9,11]$ and low on/off current ratio $[8,12]$. OTFTs with moderate-k value dielectrics such as aluminium oxide $(\mathrm{k} \sim 6.2)[13,14]$ have achieved low operating voltages through reduction in thickness [15]. However, very thin aluminium oxide layers exhibit high leakage currents, e.g. $>10^{-6} \mathrm{~A} / \mathrm{cm}^{2}$ at $2 \mathrm{~V}$ [15]. Hence, these ultra-thin dielectrics have their limitations in OTFTs.

To obtain low leakage current with aluminium oxide, the oxide surface has been modified with polymer layers [16-19] or self-assembled monolayers (SAMs) [20-26]. Along with low leakage current density, the polymer surface yielded very low surface roughness of $\leq 0.3 \mathrm{~nm}$ and transistor operating voltages of about 6 to $8 \mathrm{~V}$. Further reduction in OTFT operating voltages down to $3 \mathrm{~V}$ was achieved with SAMs. Among SAMs the alkyl phosphonic acids are the most studied.

Longer-chain alkyl phosphonic acids are more explored [2]. The study of the alkyl chain length on OTFTs showed that alkyl phosphonic acids with fewer than ten carbon atoms, assembled from solutions, form disordered monolayers [21]. This is a result of weaker 
cohesive interaction between molecules leading to OTFTs with high gate leakage current, e.g. $10^{-9}$ A for n-hexylphosphonic acid. Similar study found poor insulating properties of n-hexylphosphonic acid $\left(\mathrm{C}_{6} \mathrm{PA}\right) \mathrm{SAM}$ and low transistor field-effect mobility for $\mathrm{n}$ decylphosphonic acid ( $\left.\mathrm{C}_{10} \mathrm{PA}\right) \mathrm{SAM}$ [20]. Longer chain $\mathrm{C}_{18} \mathrm{PA}$ and anthryl-alkyl-phosphonic acid SAMs were used to improve the insulating properties of the oxide layers [23, 27].

To date the self-assembled monolayers based on alkyl phosphonic acids [20-27] have been obtained by solution process only. In this paper we present that such monolayers can be prepared by dry method as well. We use vacuum thermal evaporation to deposit monolayers of n-octylphosphonic acid $\left(\mathrm{C}_{8} \mathrm{PA}\right)$. To our knowledge, this is the first demonstration of dry growth of $\mathrm{C}_{8} \mathrm{PA}$ monolayer and its successful implementation in pentacene based OTFTs. (In the past, Halik et al.[28] and DiBenedetto et al. [29] used dry fabrication method for silane based monolayers and self-assembled nanodielectrics, respectively.) Pentacene was selected because it is the most understood organic semiconductor and its interface with solutiondeposited alkyl phosphonic acids has been studied [20, 21]. To grow a monolayer, the thickness corresponding to several $\mathrm{C}_{8} \mathrm{PA}$ monolayers is deposited, followed by a thermal desorption of physisorbed $\mathrm{C}_{8} \mathrm{PA}$ molecules. Only $\mathrm{C}_{8} \mathrm{PA}$ molecules chemically bonded to the surface of aluminium oxide remain. The implementation of this procedure into OTFTs based on small molecule conjugated polymers opens up the possibility for completely dry OTFT fabrication process amenable to roll-to-roll processing.

\section{Fabrication of metal-insulator-metal structures and OTFTs}

Metal-insulator-metal (MIM) or capacitor structures were fabricated to study the properties of the gate dielectric. 20-nm-thick aluminium lines were deposited on a glass substrate (Eagle 2000). One end of the line was capped by gold layer to prevent its oxidation. $\mathrm{AlO}_{\mathrm{x}}$ was prepared by exposing $\mathrm{Al}$ to UV/ozone in ambient atmosphere for 60 minutes. To 
prevent the contamination of the oxidizing surface, UVOCS UV/ozone cleaner was enclosed under a Hepa filter. $\mathrm{AlO}_{\mathrm{x}}$ preparation by UV/ozone oxidation of thermally evaporated aluminium has been reported elsewhere [30]. Approximately 10-nm-thick (9 monolayers) $\mathrm{C}_{8} \mathrm{PA}$ layer was thermally evaporated on top of $\mathrm{AlO}_{\mathrm{x}}$ at room temperature. Afterwards the substrate temperature was set to $160^{\circ} \mathrm{C}$ to remove all physisorbed $\mathrm{C}_{8} \mathrm{PA}$ molecules at a pressure of $<10^{-6}$ mbar. Desorption times of 25, 60, 90, and 210-minutes were selected. Taking into account the temperature profile of the heated sample, we estimated that the 10nm-thick $\mathrm{C}_{8} \mathrm{PA}$ layer would completely evaporate in $\sim 30$ minutes. However, if chemical bonding occurs between $\mathrm{C}_{8} \mathrm{PA}$ molecules and the $\mathrm{AlO}_{\mathrm{x}}$ surface, the substrate temperature would not be high enough to break these bonds. Finally, 50-nm-thick gold contacts were evaporated to complete the MIM structures. Several MIM structures were fabricated for each $\mathrm{C}_{8} \mathrm{PA}$ desorption time. In addition, $\mathrm{AlO}_{\mathrm{x}} \mathrm{MIM}$ structures with no $\mathrm{C}_{8} \mathrm{PA}$ layer were prepared as reference.

Bottom-gate, top-contact OTFTs based on thermally evaporated pentacene followed the same fabrication procedure. After $\mathrm{C}_{8} \mathrm{PA}$ desorption, a 50-nm-thick pentacene layer was deposited at a rate of $0.24 \AA / s$ at room temperature. Vacuum sublimation pentacene purification was performed in a three-zone tube furnace at a pressure of $\sim 1 \times 10^{-5} \mathrm{mBar}$. Such four-time purified pentacene had previously provided OTFTs with higher field-effect mobility than a three-time purified pentacene from Sigma-Aldrich [31]. The transistors were completed by evaporating gold source and drain contacts and their cross-section is shown in figure 1. All fabrication steps were performed by using shadow masks. The fabricated transistors have channel lengths of $30,50,70$, and $90 \mu \mathrm{m}$ and a channel width of $1000 \mu \mathrm{m}$. The W/L > 10 to minimize the effect of extending electric field lines that could lead to an overestimate of the field-effect mobility [32]. Transistors and capacitors were fabricated side by side and all thermal evaporation steps were conducted in Minispectros (Kurt J. Lesker) 
high vacuum system ( 10 $0^{-7} \mathrm{mBar}$ ) enclosed in a $\mathrm{N}_{2}$-filled glove box with $\mathrm{O}_{2}$ and $\mathrm{H}_{2} \mathrm{O}$ content less than 1 particle-per-million.

The capacitor and transistor measurements were performed with Agilent B1500A semiconductor device analyzer under ambient environmental conditions. The dielectric capacitance of MIM structures was measured between $1 \mathrm{kHz}$ and $1 \mathrm{MHz}$. The MIM current density was measured between -3 and $3 \mathrm{~V}$. In addition, the current-voltage measurement was extended to higher values to measure the dielectric breakdown voltage. We define the breakdown voltage as voltage at which the current through the MIM structure is $1 \mathrm{~mA} / \mathrm{cm}^{2}$. The transfer and output characteristics of the OTFTs were measured in a sweep mode. Transistor hysteresis was obtained by stepping the gate voltage from positive to negative values and back. Multiple MIM structures and transistors were measured for each $\mathrm{C}_{8} \mathrm{PA}$ desorption time. Mean values and standard deviations were calculated for all parameters.

The surface topography of the gate dielectric and pentacene was studied by atomic force microscopy (AFM) using the tapping mode. The scanned images were of $1 \times 1 \mu \mathrm{m}^{2}$ area. Water contact angle measurements of $\mathrm{AlO}_{\mathrm{x}}$ and $\mathrm{AlO}_{\mathrm{x}} / \mathrm{C}_{8} \mathrm{PA}$ surfaces were performed in ambient air with Krüss DSA30B goniometer.

\section{Results}

\subsection{Properties of the gate dielectric}

Properties of bare $\mathrm{AlO}_{\mathrm{x}}$ and $\mathrm{AlO}_{\mathrm{x}}$ functionalized with n-octylphosphonic acid $\left(\mathrm{AlO}_{\mathrm{x}} / \mathrm{C}_{8} \mathrm{PA}\right)$ were investigated as a function of $\mathrm{C}_{8} \mathrm{PA}$ desorption time. Figure $2 \mathrm{a}$ shows the average capacitance per unit area $\left(\mathrm{F} / \mathrm{cm}^{2}\right)$. The capacitance of bare $\mathrm{AlO}_{\mathrm{x}}$ is $0.63 \pm 0.01 \mu \mathrm{F} / \mathrm{cm}^{2}$. $\mathrm{AlO}_{\mathrm{x}} / \mathrm{C}_{8} \mathrm{PA}$ capacitance value is lower and it increases from 0.41 to $0.46 \mu \mathrm{F} / \mathrm{cm}^{2}$ as the $\mathrm{C}_{8} \mathrm{PA}$ desorption time rises from 25 to 210 minutes. The total gate dielectric capacitance $\left(\mathrm{C}_{\text {diel }}\right)$ of $\mathrm{AlO}_{\mathrm{x}} / \mathrm{C}_{8} \mathrm{PA}$ dielectric consists of the capacitance of the oxide $\left(\mathrm{C}_{\mathrm{AlOx}}\right)$ and the phosphonic acid 
layer $\left(\mathrm{C}_{\mathrm{C} 8 \mathrm{PA}}\right)$ connected in series and is given by $1 / \mathrm{C}_{\mathrm{diel}}=1 / \mathrm{C}_{\mathrm{AlOx}}+1 / \mathrm{C}_{\mathrm{C} 8 \mathrm{PA}} \cdot \mathrm{C}_{\mathrm{AlOx}}$ is the same in all capacitors since their aluminium oxide was prepared at the same time. Measured values of $\mathrm{C}_{\text {diel }}$ and $\mathrm{C}_{\mathrm{AlOx}}$ allowed us to calculate $\mathrm{C}_{\mathrm{C} 8 \mathrm{PA}}$ for each desorption time. The relative permittivity of $\mathrm{AlO}_{\mathrm{x}}$ is $\sim 6.8$ [30] leading to its thickness of $9.5 \mathrm{~nm} . \mathrm{C}_{8} \mathrm{PA}$ thickness calculated from the capacitance values using the relative permittivity of 2.1 [33] is shown in figure $2 \mathrm{~b}$. The thickness of the as-deposited $\mathrm{C}_{8}$ PAlayer, determined from AFM, is shown as well.

Figure 3a shows the leakage current densities of $\mathrm{AlO}_{\mathrm{x}}$ and $\mathrm{AlO}_{\mathrm{x}} / \mathrm{C}_{8} \mathrm{PA}$ dielectrics at various $\mathrm{C}_{8} \mathrm{PA}$ desorption times. The leakage current density through $\mathrm{AlO}_{\mathrm{x}}$ and $\mathrm{AlO}_{\mathrm{x}} / \mathrm{C}_{8} \mathrm{PA}$ dielectric is $\sim 6 \times 10^{-7}$ and $\sim 10^{-7} \mathrm{~A} / \mathrm{cm}^{2}$ at the voltage of $-3 \mathrm{~V}$, respectively, although some $\mathrm{AlO}_{\mathrm{x}} / \mathrm{C}_{8} \mathrm{PA}$ structures exhibit leakage current density as low as $4 \times 10^{-8} \mathrm{~A} / \mathrm{cm}^{2}$.

The dielectric breakdown voltages are shown in figure $3 \mathrm{~b}$. The mean breakdown voltage of $\mathrm{AlO}_{\mathrm{x}}$ and $\mathrm{AlO}_{\mathrm{x}} / \mathrm{C}_{8} \mathrm{PA}$ is $\sim 5$ and $\sim 6.2 \mathrm{~V}$, respectively. The breakdown voltage and the leakage current density of $\mathrm{AlO}_{\mathrm{x}} / \mathrm{C}_{8} \mathrm{PA}$ MIM structures do not change much with the applied desorption time. The electric breakdown field of $\mathrm{AlO}_{\mathrm{x}}$ and $\mathrm{AlO}_{\mathrm{x}} / \mathrm{C}_{8} \mathrm{PA}$ calculated from the above layer thickness is $\sim 5$ and $\sim 6 \mathrm{MV} / \mathrm{cm}$, respectively.

Figure 4a shows AFM image of $\mathrm{AlO}_{\mathrm{x}}$ surface with average root-mean-square (RMS) surface roughness of $0.45 \mathrm{~nm}$. Figures $4 \mathrm{~b}$ shows $\mathrm{AFM}$ image of $\mathrm{C}_{8} \mathrm{PA}$ surface immediately after deposition while figures $4 \mathrm{c}$ and $4 \mathrm{~d}$ depict the $\mathrm{C}_{8} \mathrm{PA}$ surface after a 25- and 210-minute desorption, respectively. As-deposited $\mathrm{C}_{8} \mathrm{PA}$ exhibits very high RMS surface roughness of $4.5 \mathrm{~nm}$. RMS roughness of 0.48 and $0.36 \mathrm{~nm}$ is achieved for $\mathrm{C}_{8} \mathrm{PA}$ surface after the $25-$ and 210-minute desorption, respectively. The surface roughness of both desorbed $\mathrm{C}_{8} \mathrm{PA}$ layers is similar to that of bare $\mathrm{AlO}_{\mathrm{x}}$, with the latter surpassing $\mathrm{AlO}_{\mathrm{x}}$ surface roughness. One could also notice similar features on the surface of bare $\mathrm{AlO}_{\mathrm{x}}$ and the surface of $\mathrm{C}_{8} \mathrm{PA}$ after the 210- 
minute desorption. In addition, the similarities in the AFM topography in figures $4 \mathrm{a}$ and $4 \mathrm{~d}$ confirm that the thermal desorption step did not lead to Al crystallization.

The corresponding water contact angles are shown in figures $4 \mathrm{e}-4 \mathrm{~h} . \mathrm{AlO}_{\mathrm{x}}$ surface is hydrophilic with a contact angle of $46.6^{\circ} \pm 0.2^{\circ}$. As-deposited, 10-nm thick $\mathrm{C}_{8} \mathrm{PA}$ surface is hydrophobic with a contact angle of $101.5^{\circ} \pm 0.3^{\circ}$. This contact angle is increased when the desorption time is increased from 25 to 210 minutes, leading to a water contact angle of $107.4^{\circ} \pm 0.5^{\circ}$ for the latter.

In summary, various measurement techniques confirm the presence of n-octylphosphonic acid monolayer formed by thermal evaporation. The as-deposited, $\sim 10$ nm-thick $\mathrm{C}_{8} \mathrm{PA}$ layer is reduced down to a monolayer $(\sim 1-\mathrm{nm})$ by removing the nonchemically bonded $\mathrm{C}_{8} \mathrm{PA}$ molecules via thermal heating. The measurements show that although this process is completed in approximately 30 minutes, the monolayer is present even after 3 hours of additional heating. Functionalizing the $\mathrm{AlO}_{\mathrm{x}}$ surface with thermally evaporated $\mathrm{C}_{8} \mathrm{PA}$ monolayer lowers the leakage current density to $\sim 10^{-7} \mathrm{~A} / \mathrm{cm}^{2}$ at $3 \mathrm{~V}$, increases the breakdown voltage to $6.2 \mathrm{~V}$ and the breakdown field to $\sim 6 \mathrm{MV} / \mathrm{cm}$ and renders the surface hydrophobic with a water contact angle of $107.4^{\circ} \pm 0.5^{\circ}$.

\subsection{OTFT properties}

Properties of OTFTs with $\mathrm{AlO}_{\mathrm{x}} / \mathrm{C}_{8} \mathrm{PA}$ dielectrics are presented next. Transfer characteristics of OTFTs employing $\mathrm{C}_{8} \mathrm{PA}$ with the 210-minute desorption are shown in figure $5 \mathrm{a}$ for drain voltages of -0.1 and $-2 \mathrm{~V}$. Figure $5 \mathrm{~b}$ shows the corresponding output characteristics for the gate voltages of $0,-0.5,-1.0,-1.5$, and $-2.0 \mathrm{~V}$.

Figure 6 depicts the field-effect mobility (6a), threshold voltage (6b), inverse subthreshold slope (6c), off-current (6d), and on/off current ratio (6e) as functions of $\mathrm{C}_{8} \mathrm{PA}$ desorption time. The field-effect mobility is calculated using standard MOSFET equations. It 
is extracted from the linear fit of $I_{\mathrm{D}}$ ( or $\sqrt{I_{D}}$ ) versus $V_{\mathrm{G}}$ and the intercept on the voltage axis corresponds to the threshold voltage. The subthreshold slope $S$ is calculated as an inverse of the slope of $\log \left(I_{\mathrm{D}}\right)$ versus $V_{\mathrm{G}}$. The on- and off-currents are the maximum and minimum drain currents at $V_{\mathrm{D}}=-2 \mathrm{~V}$.

The transfer characteristic hysteresis between forward (off-to-on) and reverse (on-tooff) directions is shown in figure 7 for OTFTs with $\mathrm{C}_{8}$ PA after 25-minute and 210-minute desorption times. The hysteresis is taken as $\Delta V_{G}$ between the forward and backward $V_{G}$ sweeps at $V_{D}=-2 \mathrm{~V}$ and $I_{D}=4 \times 10^{-8} \mathrm{~A}$.

When $\mathrm{C}_{8} \mathrm{PA}$ desorption time was increased from 25 to 210 minutes, the field-effect mobility increased from $\sim 0.02 \mathrm{~cm}^{2} / \mathrm{Vs}$ to $\sim 0.04 \mathrm{~cm}^{2} / \mathrm{Vs}$, the threshold voltage rose from $\sim-1.2 \mathrm{~V}$ to $\sim-1.4 \mathrm{~V}$, the sub-threshold slope decreased from $\sim 120 \mathrm{mV} /$ decade to $\sim 80$ $\mathrm{mV} /$ decade, the off-current decreased from $\sim 5 \times 10^{-12} \mathrm{~A}$ to $\sim 1 \times 10^{-12} \mathrm{~A}$, and the hysteresis decreased from 61 to $26 \mathrm{mV}$. The reduction in the off-current also led to an increase in the on/off current ratio from $\sim 3.8 \times 10^{4}$ to $\sim 2.5 \times 10^{5}$. To better understand this improvement in OTFT parameters, figure 8 shows AFM images of 50-nm-thick pentacene deposited on $\mathrm{AlO}_{\mathrm{x}} / \mathrm{C}_{8} \mathrm{PA}$ after the 25 -minute (figure $8 \mathrm{~b}$ ) and 210-minute (figure 8c) desorption. Figure $8 \mathrm{a}$ shows pentacene deposited directly on top of $\mathrm{AlO}_{\mathrm{x}}$ for comparison. Figures $8 \mathrm{a}$ (bare $\mathrm{AlO}_{\mathrm{x}}$ ) and $8 \mathrm{~b}\left(\mathrm{AlO}_{\mathrm{x}} / \mathrm{C}_{8} \mathrm{PA}\right.$ with 25 -minute desorption time $)$ show similar pentacene topography. In both cases the larger grains of $\sim 150$-nm diameter contain subgrains. The subgrain structure is suppressed in figure $8 \mathrm{c}\left(\mathrm{AlO}_{\mathrm{x}} / \mathrm{C}_{8} \mathrm{PA}\right.$ with 210 -minute desorption time $)$, although the overall pentacene grain size is slightly smaller.

\section{Discussion}

According to Hoque et al. [34] reaction between alkyl phosphonic acid and aluminium oxide is $\mathrm{R}-\mathrm{PO}(\mathrm{OH})_{2}+\mathrm{HO}-\mathrm{Al}-\rightarrow \mathrm{R}-(\mathrm{OH}) \mathrm{OP}-\mathrm{O}-\mathrm{Al}-+\mathrm{H}_{2} \mathrm{O}$ where $\mathrm{R}-\mathrm{PO}(\mathrm{OH})_{2}$ 
represents alkyl phosphonic acid and $\mathrm{HO}-\mathrm{Al}$ - is the surface of aluminium terminated with hydroxyl groups. Tsud et al. [35] demonstrated vacuum vapour deposition of phenylphosphonic acid on aluminium oxide that resulted in a formation of phosphonate interface (Al-O-P) with an outward phenyl ring. The data presented in figures 2,3 , and 4 confirm formation of n-octyl phosphonic acid monolayer on the surface of $\mathrm{AlO}_{\mathrm{x}}$. The layer remains on the surface of the aluminium oxide even after prolonged heating of the surface. This is possible only if the $\mathrm{C}_{8} \mathrm{PA}$ monolayer is chemically bonded to the $\mathrm{AlO}_{\mathrm{x}}$ surface because the surface is held at a temperature at which the $\mathrm{C}_{8} \mathrm{PA}$ source material readily evaporates.

The thickness of the $\mathrm{AlO}_{\mathrm{x}}$ formed by UV/ozone oxidation is in agreement with our previous experiments [30]. $\mathrm{C}_{8} \mathrm{PA}$ thickness reaches value of about $1.1 \mathrm{~nm}$ after 90 -minute desorption time. This value is similar to that calculated by Jedaa et al. [20]. No change in the $\mathrm{C}_{8} \mathrm{PA}$ thickness is observed after another 120 minutes of heating. Hence, it can be concluded that the $\mathrm{C}_{8} \mathrm{PA}$ monolayer prepared by thermal evaporation is attached to the surface of $\mathrm{AlO}_{\mathrm{x}}$. The current density of $\mathrm{AlO}_{\mathrm{x}} / \mathrm{C}_{8} \mathrm{PA}$ is almost the same for all desorption times with slightly smaller value at 210 minutes. $\mathrm{AlO}_{\mathrm{x}} / \mathrm{C}_{8} \mathrm{PA}$ dielectrics exhibit about an order of magnitude lower leakage current densities than bare $\mathrm{AlO}_{\mathrm{x}}$. The leakage current density of our $\mathrm{AlO}_{\mathrm{x}} / \mathrm{C}_{8} \mathrm{PA}$ bi-layer is similar to that reported by Klauk et al. [2] for $\mathrm{AlO}_{\mathrm{x}} / \mathrm{C}_{18} \mathrm{PA}$. The leakage current density obtained in this work using alkyl phosphonic acid with short alkyl chain $\left(\mathrm{C}_{8} \mathrm{PA}\right)$ is also similar to that obtained for alkyl phosphonic acid with longer chain $\left(\mathrm{C}_{18} \mathrm{PA}\right)$ by Ma et al. [23], Wöbkenberg et al. [26], and Jedaa et al. [20].

The breakdown voltage of $\mathrm{AlO}_{\mathrm{x}} / \mathrm{C}_{8} \mathrm{PA}$ dielectric is about 1.2 volts higher than that of $\mathrm{AlO}_{\mathrm{x}}$ without $\mathrm{C}_{8} \mathrm{PA}$. The breakdown voltage and the electric breakdown field are similar to those reported in [20]. However, the breakdown field is much higher than that achieved for thicker dielectrics based on aluminium oxide coated with polymer layer [18]. 
The AFM topography shown in figure $4 \mathrm{~b}$ reveals that the as-deposited $\mathrm{C}_{8} \mathrm{PA}$ layer is very rough. The surface morphology and RMS roughness change rapidly after desorption of the non-bonded $\mathrm{C}_{8} \mathrm{PA}$ molecules, slightly surpassing the RMS roughness of $\mathrm{AlO}_{\mathrm{x}}$ after the 210 minutes of desorption. The roughness values are in contrast to the results reported by Ma et al. [23] and Ashall et al. [19] who reported that the surface roughness of phosphonic acid monolayer was higher than that of the underlying oxide. By studying the alkyl phosphonic acids with different alkyl chain lengths, Fukuda et al. [21] found the minimum surface roughness of $0.76 \mathrm{~nm}$ for $\mathrm{C}_{14} \mathrm{PA}$ and suggested that the lower surface roughness was correlated with tighter packing density of the molecules. Our $\mathrm{AlO}_{\mathrm{x}} / \mathrm{C}_{8} \mathrm{PA}$ exhibits RMS surface roughness of $0.36 \mathrm{~nm}$ after a 210 -minute desorption which is the lowest value for alkyl phosphonic acids reported to date. Such small surface roughness is comparable to that achieved with polymer dielectrics [18]. The hydrophobicity of the $\mathrm{C}_{8} \mathrm{PA}$ surface is improved when the desorption time is increased from 25 to 210 minutes, leading to a water contact angle of $107.4^{\circ} \pm 0.5^{\circ}$ for the latter. This value is similar to the value reported for $\mathrm{C}_{18} \mathrm{PA}$ monolayers assembled from solutions [36]. The reduction in the leakage current density, increase in the breakdown electric field and improvement in the surface roughness confirm that dry $\mathrm{C}_{8} \mathrm{PA}$ monolayer provides good step coverage and offers an alternative path to alkyl phosphonic acid monolayers prepared from solution.

Pentacene morphology is known to dependent on the type of dielectric [37-39], the dielectric surface roughness [40] and its surface energy [41]. AFM images presented in figure 8 reveal that the pentacene grain size is $\sim 100 \mathrm{~nm}$ when it grows on $\mathrm{AlO}_{\mathrm{x}} / \mathrm{C}_{8} \mathrm{PA}$ after the 210-minute desorption. This grain size is comparable to thermally evaporated pentacene on $\mathrm{Al}_{2} \mathrm{O}_{3} / \mathrm{OTS}$ [16], $\mathrm{AlO}_{\mathrm{x}}$ and $\mathrm{AlO}_{\mathrm{x}} / \mathrm{C}_{18} \mathrm{PA}$ [19], $\mathrm{HfO}_{2} / \mathrm{PA}$ [27], $\mathrm{SiO}_{2} / \mathrm{OTS}[38,42,43]$ and low surface energy polyimide-siloxane [41] (OTS stands for octadecyltrichlorosilane). The similar surface roughness of $\mathrm{AlO}_{\mathrm{x}}$ and $\mathrm{AlO}_{\mathrm{x}} / \mathrm{C}_{8} \mathrm{PA}$ after the 25-minute desorption step 
resulted in comparable pentacene morphology, in spite of the different surface energies of the underlying dielectrics.

The performance of our OTFTs is comparable to OTFTs that implement alkyl phosphonic acids assembled from solution. The drain current is three orders of magnitude higher than the gate current, demonstrating good insulating properties of the dielectric bilayer. This ratio is higher than that for pentacene-based OTFTs with $\mathrm{C}_{14} \mathrm{PA}[20,25]$ and lower than that for pentacene based OTFTs with $\mathrm{C}_{18} \mathrm{PA}$ [2]. The negligible hysteresis observed for OTFTs implementing $\mathrm{C}_{8} \mathrm{PA}$ with the 210-minute desorption confirms a low-trap dielectric/semiconductor interface.

The maximum field-effect mobility is $0.04 \mathrm{~cm}^{2} / \mathrm{Vs}$. This is comparable to mobility achieved with $\mathrm{C}_{6} \mathrm{PA}$ by Jedaa et al. [20]. The increase in the mobility with increasing $\mathrm{C}_{8} \mathrm{PA}$ desorption time is correlated with lower surface roughness of $\mathrm{C}_{8} \mathrm{PA}$ monolayer. Higher fieldeffect mobility was achieved for similar OTFT structures with pentacene dendrites that are several micrometers in size [21]. Our pentacene grains are $~ 100 \mathrm{~nm}$ in diameter (figure 8) and lead to field-effect mobility of $0.04 \mathrm{~cm}^{2} / \mathrm{Vs}$. This is 1 order of magnitude lower than the mobility of OTFTs with pentacene dendrites of 2-3 $\mu \mathrm{m}$ in size [21]. Consequently, the OTFT mobility is well correlated with the pentacene morphology.

The OTFT threshold voltage increases from $\sim-1.2 \mathrm{~V}$ to $\sim-1.4 \mathrm{~V}$ as the $\mathrm{C}_{8} \mathrm{PA}$ desorption time increases from 25 to 210 minutes. According to Zhang et al. [16], improper passivation of $-\mathrm{Al}-\mathrm{OH}$ results in earlier turn-on voltage and lower threshold voltage of the transistors. The low threshold voltage can result in higher off-current and, consequently, lower on/off current ratio $[16,44]$. OTFTs with $\mathrm{C}_{8} \mathrm{PA}$ desorbed for 210 minutes exhibit the lowest off-current, the highest on/off current ratio and the highest threshold voltage among the fabricated OTFTs. The on/off current ratio is the best among OTFTs with alkyl phosphonic acids of short alkyl chains reported to date [20,21]. The achieved on/off current 
ratio is also higher than that obtained for pentacene OTFTs with $\mathrm{Al}_{2} \mathrm{O}_{3} / \mathrm{OTS}$ [16], $\mathrm{HfO}_{2} / \mathrm{C}_{18} \mathrm{PA}$ [27], $\mathrm{AlO}_{\mathrm{x}} / \mathrm{C}_{10} \mathrm{PA}$ and $\mathrm{AlO}_{\mathrm{x}} / \mathrm{C}_{18} \mathrm{PA}$ [21] dielectrics. It is however smaller than that reported by Klauk et al. for pentacene OTFTs with $\mathrm{AlO}_{\mathrm{x}} / \mathrm{C}_{18} \mathrm{PA}$ dielectrics [2].

The reduction in the subthreshold slope with increasing desorption time is likely a result of the $\mathrm{C}_{8} \mathrm{PA}$ surface having low surface roughness and low density of traps, similarly to effects observed in $[16,19,23]$. The lowest subthreshold slope of $80 \mathrm{mV} / \mathrm{decade}$ achieved after the 210-minute $\mathrm{C}_{8} \mathrm{PA}$ desorption is only slightly higher than the best reported value of $75 \mathrm{mV} /$ decade for the interface between an alkyl phosphonic acid monolayer and pentacene [39].

The hysteresis in the transfer characteristic reflects charge trapping sites [16]. According to figure 7 the number of these sites is reduced when the desorption time is increased, with negligible hysteresis for transistors implementing $\mathrm{C}_{8} \mathrm{PA}$ desorbed for 210 minutes.

When considering all results collectively, one must conclude that the post-deposition heating (desorption step) of $\mathrm{C}_{8} \mathrm{PA}$ layer has dual function. It removes all physisorbed molecules down to a single layer and subsequently anneals the remaining $\mathrm{C}_{8} \mathrm{PA}$ monolayer. The desorption temperature is high enough to counteract the weak interaction between the alkyl chains of the neighbouring molecules. Even though the molecules in the $\mathrm{C}_{8} \mathrm{PA}$ monolayer are attached to $\mathrm{AlO}_{\mathrm{x}}$ surface, the thermal energy supplied during the desorption step would allow minor realignment of the molecules to minimize the energy of the system.

\section{Conclusions}

We developed a dry method for deposition of $\mathrm{C}_{8} \mathrm{PA}$ monolayer on aluminium oxide that would be amenable to roll-to-roll dry fabrication. Vacuum thermal evaporation is used to deposit monolayers of n-octyl phosphonic acid $\left(\mathrm{C}_{8} \mathrm{PA}\right)$ on aluminium oxide prepared by 
UV/ozone oxidation. To grow a monolayer, the thickness corresponding to several $\mathrm{C}_{8} \mathrm{PA}$ monolayers is deposited, followed by a thermal desorption of the physisorbed molecules. Capacitance and $\mathrm{I}-\mathrm{V}$ measurements of metal-insulator-metal structures containing $\mathrm{AlO}_{\mathrm{x}} / \mathrm{C}_{8} \mathrm{PA}$ dielectric confirm that only $\mathrm{C}_{8} \mathrm{PA}$ molecules attached to the surface of aluminium oxide remain. When $\mathrm{C}_{8} \mathrm{PA}$ monolayer is thermally evaporated on a 9.5-nm-thick $\mathrm{AlO}_{\mathrm{x}}$ with $\mathrm{RMS}$ surface roughness of $0.45 \mathrm{~nm}$, the leakage current density is reduced by $\sim$ an order of magnitude and the breakdown voltage is increased by $\sim 1.2 \mathrm{~V}$. The AFM measurements show that the RMS roughness of the optimized $\mathrm{C}_{8} \mathrm{PA}$ surface is $0.36 \mathrm{~nm}$. This value is comparable to polymer dielectrics and smaller than the values previously reported for alkyl phosphonic acids. In addition, the water contact angle measurement of the optimized $\mathrm{C}_{8} \mathrm{PA}$ surface is $107.4^{\circ} \pm 0.5^{\circ}$, a value similar to that of $\mathrm{C}_{18} \mathrm{PA}$ monolayers assembled from solutions.

To provide practical demonstration of this procedure, low-voltage OTFTs based on pentacene and dry $\mathrm{AlO}_{\mathrm{x}} / \mathrm{C}_{8} \mathrm{PA}$ gate dielectric bi-layer were fabricated. They operate within 3 V and exhibit good linear/saturation behaviour characteristics. However, the OTFT parameters are slightly dependent on $\mathrm{C}_{8} \mathrm{PA}$ desorption time. Increase in the $\mathrm{C}_{8} \mathrm{PA}$ desorption time leads to an increase in the field-effect mobility from $\sim 0.02 \mathrm{~cm}^{2} / \mathrm{Vs}$ to $\sim 0.04 \mathrm{~cm}^{2} / \mathrm{Vs}$, increase in the threshold voltage from $\sim-1.2 \mathrm{~V}$ to $\sim-1.4 \mathrm{~V}$, decrease in the sub-threshold slope from $\sim 120 \mathrm{mV} /$ decade to $\sim 80 \mathrm{mV} /$ decade, decrease in the off-current from $\sim 5 \times 10^{-12}$ A to $\sim 1 \times 10^{-12} \mathrm{~A}$, increase in the on/off current ratio from $\sim 3 \times 10^{4}$ to $\sim 2.3 \times 10^{5}$ and a decrease in the transistor hysteresis from 61 to $26 \mathrm{mV}$. These results collectively suggest that the applied desorption step removes all physisorbed $\mathrm{C}_{8} \mathrm{PA}$ molecules down to a single layer and reduces the density of defect sites in the remaining $\mathrm{C}_{8} \mathrm{PA}$ monolayer bonded to $\mathrm{AlO}_{\mathrm{x}}$ surface.

\section{Acknowledgements}


The authors thank the School of Engineering of the University of Glasgow for the transistor fabrication support. They also thank R. Ulijn, D. Uttamchandani and D. Lamprou from the University of Strathclyde for providing access and training on AFM, white light interferometry, and water contact angle measurement. This research is supported by the Scottish Funding Council through Glasgow Research Partnership in Engineering.

\section{REFERENCES}

[1] X.-H. Zhang, W.J. Potscavage, S. Choi, B. Kippelen, Appl. Phys. Lett. 94 (2009) 043312.

[2] H. Klauk, U. Zschieschang, J. Pflaum, M. Halik, Nat. 445 (2007) 745.

[3] J.B. Koo, S.J. Yun, J.W. Lim, S.H. Kim, C.H. Ku, Appl. Phys. Lett. 89 (2006) 033511

[4] K. Fukuda, T. Sekitani, T. Yokota, K. Kuribara, T.-C. Huang, T. Sakurai, U. Zschieschang, H. Klauk, M. Ikeda, H. Kuwabara, T. Yamamoto, K. Takimiya, K.-T. Cheng, T. Someya, IEEE Electron Device Lett. 32 (2011) 1448.

[5] K. Fukuda, T. Sekitani, U. Zschieschang, H. Klauk, K. Kuribara, T. Yokota, T. Sugino, K. Asaka, M. Ikeda, H. Kuwabara, T. Yamamoto, K. Takimiya, T. Fukushima, T. Aida, M. Takamiya, T Sakurai, T. Someya, Adv. Funct. Mater. 21 (2011) 4019.

[6] J.M. Rabaey, Digital integrated circuits: A design perspective. 1996.

[7] S.H. Kim, S.Y. Yang, K. Shin, H. Jeon, J.W. Lee, K.P. Hong, C.E. Park, Appl. Phys. Lett. 89 (2006) 183516.

[8] M.F. Chang, P.T. Lee, S.P. McAlister, A. Chin, IEEE Electron Device Lett. 30 (2009) 133. 
[9] L.F. Deng, P.T. Lai, W.B. Chen, J.P. Xu, Y.R. Liu, H.W. Choi, C.M. Che, IEEE Electron Device Lett. 32 (2011) 93.

[10] M.F. Chang, P.T. Lee, S.P. McAlister, A. Chin, IEEE Electron Device Lett. 29 (2008) 215.

[11] C.-Y. Wei, S.-H. Kuo, Y.-M. Hung, W.-C. Huang, F. Adriyanto, Y.-H. Wang, IEEE Electron Device Lett. 32 (2011) 90.

[12] H. Yan, H. Hanagata, T. Jo, H. Okuzaki, Jpn. J. Appl. Phys. 50 (2011) $01 B C 05$.

[13] J. Lee, J.H. Kim, S. Im, J. Appl. Phys. 95 (2004) 3733.

[14] J. Lee, J.H. Kim, S. Im, Appl. Phys. Lett. 83 (2003) 2689.

[15] K.D. Kim, C.K. Song, Appl. Phys. Lett. 88 (2006) 233508.

[16] X.-H. Zhang, S.P. Tiwari, B. Kippelen, Org. Electron. 10 (2009) 1133.

[17] H. Yang, C. Yang, S.H. Kim, M. Jang, C.E. Park, ACS Appl. Mater. Interfaces 2 (2010) 391.

[18] J.-M. Choi, D.K. Hwang, S.H.Jeong, J.H. Park, E. Kim, J.H. Kim, S.Im, J. Electrochem. Soc. 154 (2007) H331.

[19] D. Ashall, S.J. Fakher, M.F. Mabrook, IEEE international conference on Nanotechnology (2011) 61.

[20] A. Jedaa, M. Burkhardt, U. Zschieschang, H. Klauk, D. Habich, G. Schmid, M. Halik, Org. Electron. 10 (2009) 1442.

[21] K. Fukuda, T. Hamamoto, T. Yokota, T.Sekitani, U. Zschieschang, H. Klauk, T. Someya, Appl. Phys. Lett. 95 (2009) 203301.

[22] K. Fukuda, T. Yokota, K. Kuribara, T. Sekitani, U. Zschieschang, H. Klauk, T. Someya, Appl. Phys. Lett. 96 (2010) 053302.

[23] H. Ma, O. Acton, G. Ting, J.W. Ka, H.-L. Yip, N. Tucker, R. Schofield, A.K.-Y. Jen, Appl. Phys. Lett. 92 (2008) 113303. 
[24] U. Zschieschang, F. Ante, T. Yamamoto, K. Takimiya, H. Kuwabara, M. Ikeda, T. Sekitani, T. Someya, K. Kern, H. Klauk, Adv. Mater. 22 (2010) 982.

[25] M. Novak, C.M. Jäger, A. Rumpel, H. Kropp, W. Peukert, T.Clark, M. Halik, Org. Electron. 11 (2010) 1476.

[26] P.H. Wöbkenberg, J. Ball, F.B. Kooistra, J.C. Hummelen, D.M.d. Lee, D.D.C. Bradley, T.D. Anthopoulos, Appl. Phys. Lett. 93 (2008) 013303.

[27] O. Acton, G. Ting, H. Ma, J.W. Ka, H.-L. Yip, N.M. Tucker, A. K.-Y. Jen, Adv. Mater. 20 (2008) 3697.

[28] M. Halik, H. Klauk, U. Zschieschang, G. Schmid, C. Dehm, M. Schütz, S. Maisch, F. Effenberger, M. Brunnbauer, F. Stellacci, Nature, 431 (2004) 963.

[29] S.A. DiBenedetto, D.L. Frattarelli, A. Facchetti, M.A. Ratner, T.J. Marks, J. Am. Chem. Soc. 131 (2009) 11080.

[30] K. C. Chinnam, S. Gupta, and H. Gleskova, J. Non-Crystalline Solids (2012) - in press.

[31] S. Gupta, K. C. Chinnam, M. Zelzer, R. Ulijn, H. Gleskova, 2012 Spring Mat. Res. Soc. Meeeting, San Francisco, April 9-13, 2012.

[32] K. C. Chinnam and H. Gleskova, unpublished data.

[33] http://www.engineeringtoolbox.com/relative-permittivity-d_1660.html.

[34] E. Hoque, J.A. DeRose, P. Hoffmann, B. Bhushan, H.J. Mathieu, J. Phys. Chem. C $111(2007) 3956$.

[35] N. Tsud, M. Yoshitake, Surf. Sci., 601 (2007) 3060.

[36] U. Zschieschang, F. Ante, M. Schlörholz, M. Schmidt, K. Kern, H. Klauk, Adv. Mater. 22 (2010) 4489.

[37] S.-j. Mun, J.-M Choi, K.H. Lee, K. Lee, S. Im, Appl. Phys. Lett. 93 (2008) 233301.

[38] D. Knipp, R.A. Street, A. Volkel, J. Ho, J. Appl. Phys. 93 (2003) 347. 
[39] O. Acton, M. Dubey, T. Weidner, K.M. O’Malley, T.-W. Kim, G.G. Ting, D. Hutchins, J.E. Baio, T.C. Lovejoy, A.H. Gage, D.G. Castner, H. Ma, A.K. -Y. Jen, Adv. Funct. Mater. 21 (2011) 1476.

[40] S. Steudel, S.D. Vusser, S.D. Jonge, D. Janssen, S. Verlaak, J. Genoe, P. Hermans, Appl. Phys. Lett. 85 (2004) 4400.

[41] S.Y. Yang, K. Shin, C.E. Park, Adv. Funct. Mater. 15 (2005) 1806.

[42] M. Shtein, J. Mapel, J.B. Benziger, S.R. Forrest, Appl. Phys. Lett. 81 (2002) 268.

[43] S.P. Tiwari, K.A. Knauer, A. Dindar, B. Kippelen, Org. Electron. 13 (2012) 18.

[44] S.Y. Yang, S.H. Kim, K. Shin, H. Jeon, C.E. Park, Appl. Phys. Lett. 88 (2006) 173507. 
Figure captions:

1. OTFT cross-section.

2. Capacitance of $\mathrm{AlO}_{\mathrm{x}} / \mathrm{C}_{8} \mathrm{PA}$ per unit area (a) and $\mathrm{C}_{8} \mathrm{PA}$ thickness (b) as functions of $\mathrm{C}_{8} \mathrm{PA}$ desorption time. The capacitance of the reference $\mathrm{AlO}_{\mathrm{x}} \mathrm{MIM}$ structure is shown for comparison.

3. Current density (a) and breakdown voltage (b) of $\mathrm{AlO}_{\mathrm{x}} / \mathrm{C}_{8} \mathrm{PA}$ bi-layer as functions of $\mathrm{C}_{8} \mathrm{PA}$ desorption time. The current density and breakdown voltage of the reference $\mathrm{AlO}_{\mathrm{x}}$ layer are shown for comparison.

4. AFM surface images of bare $\mathrm{AlO}_{\mathrm{x}}(\mathrm{a}) ; \mathrm{C}_{8} \mathrm{PA}$ immediately after deposition (b), and after 25-minute (c) and 210-minute (d) desorptions. The contact angle measurement of the corresponding surface is shown below each AFM surface image ((e)-(h)).

5. Transfer (a) and output (b) charactersitics of OTFT with $\mathrm{L}=30 \mu \mathrm{m}$ and $\mathrm{W}=1000$ $\mu \mathrm{m} . \mathrm{C}_{8} \mathrm{PA}$ desorption time was 210 minutes. The output curves for $\mathrm{V}_{\mathrm{G}}=0,-0.5$, and $-1 \mathrm{~V}$ lie on $\mathrm{x}$-axis.

6. OTFT field-effect mobility (a), threshold voltage (b), subthreshold slope (c), offcurrent (d), and on/off current ratio (e) as functions of $\mathrm{C}_{8} \mathrm{PA}$ desorption time.

7. Transfer characteristic hysteresis of OTFTs with $\mathrm{C}_{8} \mathrm{PA}$ after 25-minute and 210minute desorptions.

8. AFM surface images of pentacene deposited on bare $\mathrm{AlO}_{\mathrm{x}}(\mathrm{a})$, and on $\mathrm{C}_{8} \mathrm{PA}$ after 25minute (b) and 210-minute (c) desorptions. 


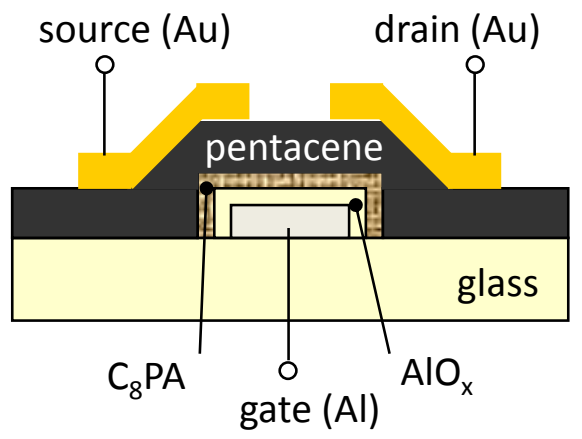



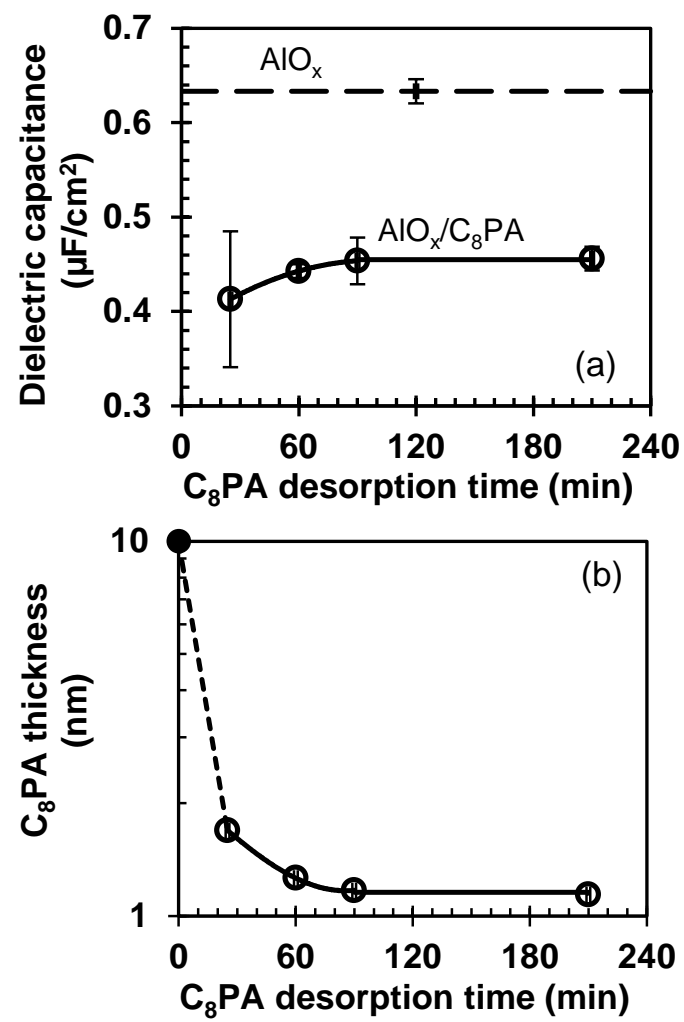

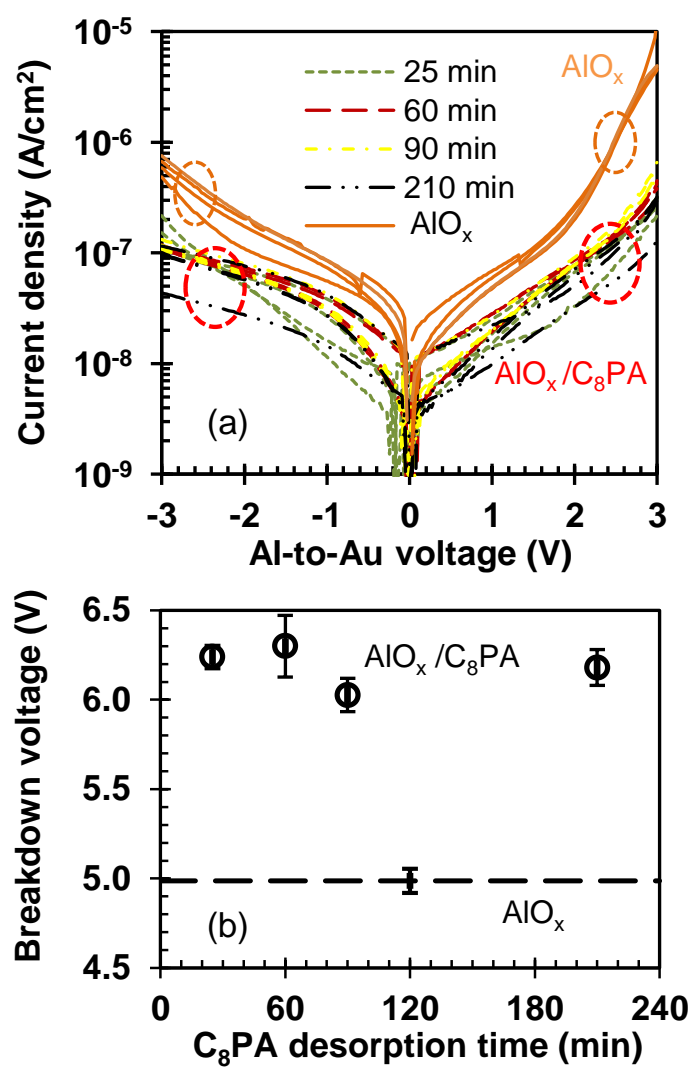


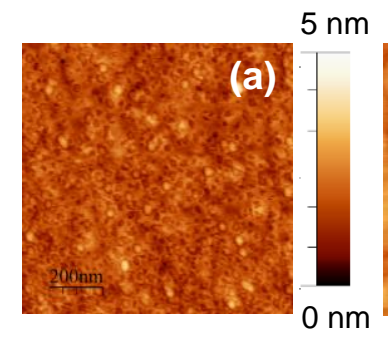

(e)

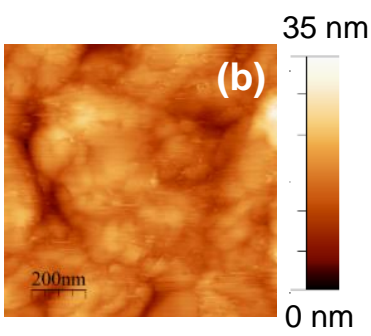

(f)

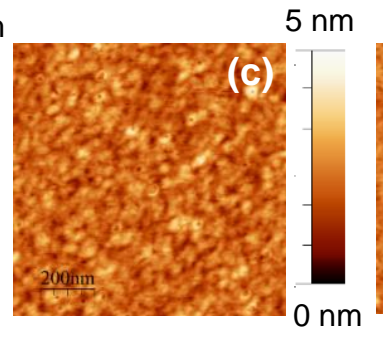

(g)
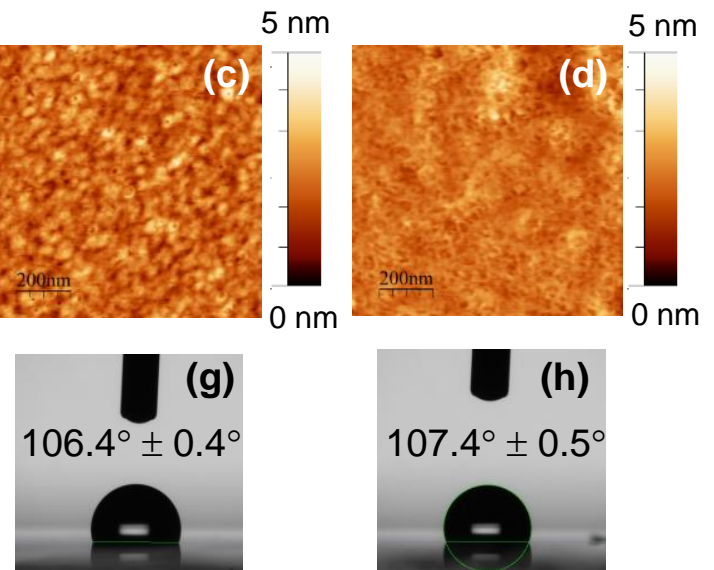

(h)

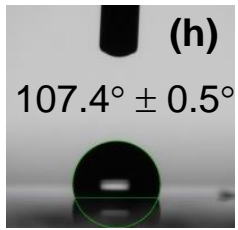

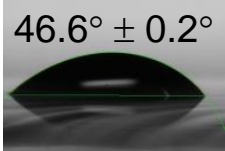

$101.5^{\circ} \pm 0.3^{\circ}$

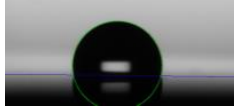



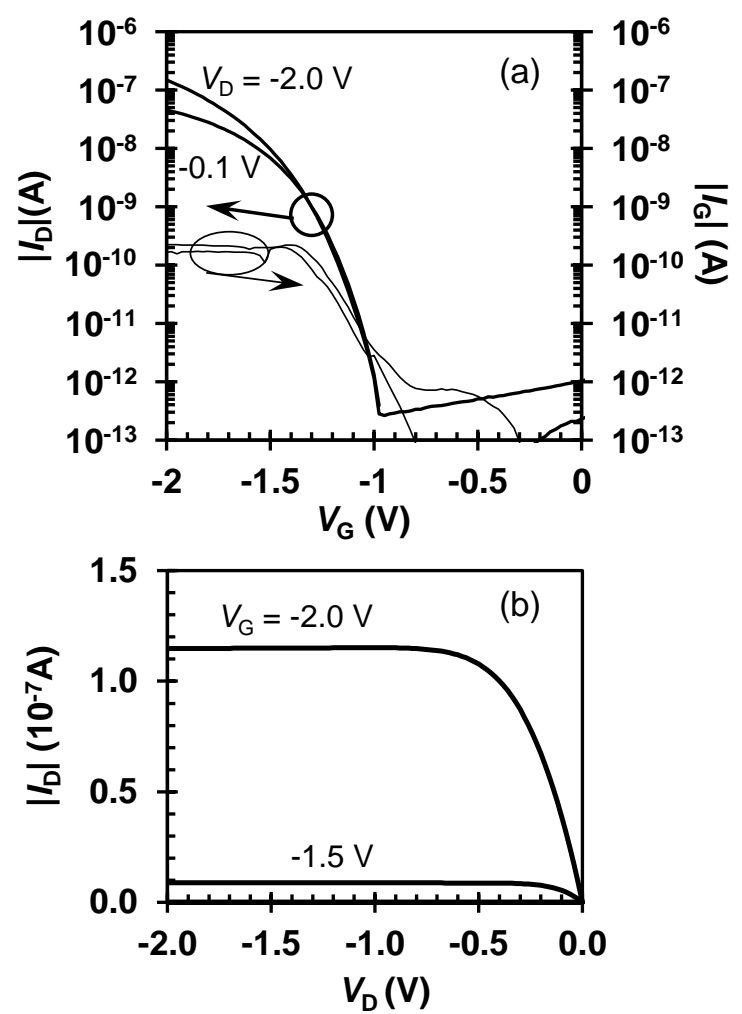


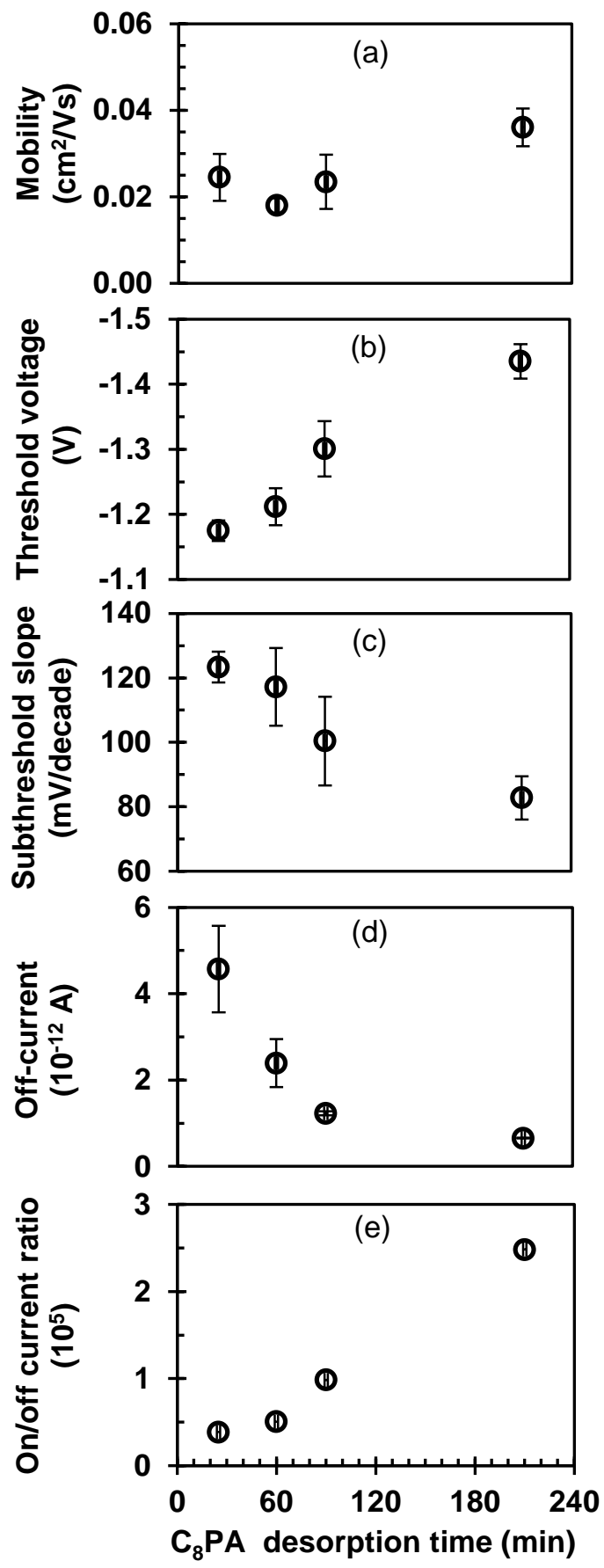




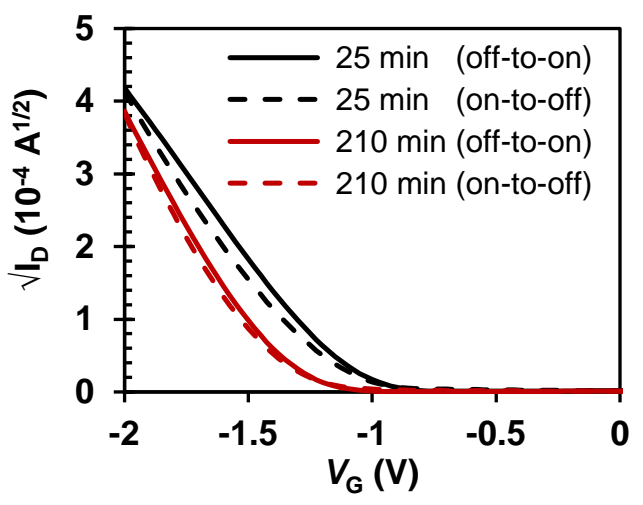



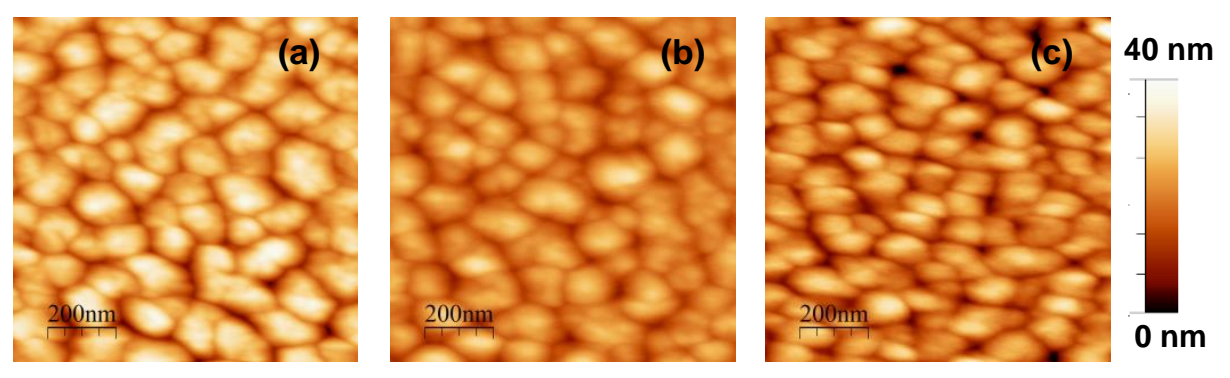